\title{
The Therapeutic Effect of Endoscopic Tumor Resection on Acromegalic Cardiomegaly in Patients With Pituitary Adenoma
}

\author{
Kaveh Ebrahimzadeh $^{1}$, Kurosh Mojtabavi $^{2}$, Sasan Mohammadi ${ }^{3}{ }^{\circledR}$, Mehrdad Farahani $^{3}{ }^{\circledR}$, Zohreh Gholizadeh \\ Ghozloujeh $^{3 \oplus}$, Sina Asaadi ${ }^{\circledR}$, Guive Sharifi $^{\circledR}$, Mohammad Amin Joshaghanian $^{3^{*}}{ }^{\circledR}$, Omidvar Rezaei $^{1}$ \\ 'Skull Base Research Center, Loghman Hakim Hospital, Shahid Beheshti University of Medical Sciences, Tehran, Iran \\ ${ }^{2}$ Cellular and Molecular Research Center \& Department of Physiology, School of Medicine, Guilan University of Medical \\ Sciences, Rasht, Iran \\ ${ }^{3}$ School of Medicine, Shahid Beheshti University of Medical Sciences, Tehran Iran \\ ${ }^{4}$ Division of Vascular and Endovascular Neurosurgery, Firoozgar Hospital, Iran University of Medical Sciences, Tehran, Iran
}

\begin{abstract}
Background: Acromegaly defines as chronic elevations of insulin-like growth factor-1 (IGF-1) and growth hormone $(\mathrm{GH})$, which results in enlargement of organs and soft tissues. Cardiovascular complications of acromegaly such as cardiomegaly, hypertension contributing to a high risk of cardiovascular events. This study aimed to identify the determinants of the prevalence of cardiomegaly as cardiovascular comorbidity of acromegaly and the potential effect of the curative intervention. Methods: A total of 160 patients with acromegaly due to pituitary adenoma participated in this study. Acromegaly diagnosed was based on clinical manifestations, age-adjusted plasma IGF-I, and elevated plasma GH levels, not suppressible during an oral glucose tolerance test $(75 \mathrm{~g})$. Electrocardiogram and chest X-ray obtained in all patients. Treatment approaches included transsphenoidal surgery and hormonal evaluation performed before and six months after surgery.

Results: The GH serum level was elevated in all patients before surgery, with a mean of $33.7 \mathrm{ng} /$ $\mathrm{mL}$ that reached $5.7 \mathrm{ng} / \mathrm{mL}$ after surgery. Mean IGF-1 was $794.1 \mathrm{ng} / \mathrm{mL}$ that reached $395.6 \mathrm{ng} / \mathrm{mL}$ postoperatively. The prevalence of cardiomegaly was $15 \%$ that improved in $5 \%$ of patients after trans sphenoidal surgery.

Conclusion: Appropriate surgical intervention in acromegaly that complicated by cardiomegaly may result in significant improvement of the cardiac structure.

Keywords: Acromegaly; pituitary adenoma; Transsphenoidal surgery; Cardiomegaly.
\end{abstract}

*Correspondence to

Mohammad Amin

Joshaghanian, School of medicine, Shahid Beheshti

University of Medical Sciences, Tehran Iran

Tel: +989121300947

Email: mohammadamin.

joshaghanian@gmail.com

Published online December 23, 2019

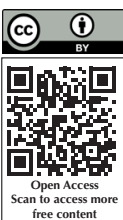

Citation: Ebrahimzadeh K, Mojtabavi K, Mohammadi S, Farahani M, Gholizadeh Ghozloujeh Z, Asaadi S, et al. The therapeutic effect of endoscopic tumor resection on acromegalic cardiomegaly in patients with pituitary adenoma. Int Clin Neurosci J. 2020;7(1):31-34. doi:10.15171/icnj.2020.05.

\section{Introduction}

Acromegaly defined as by chronic elevations of insulinlike growth factor-1 (IGF-1) and growth hormone (GH) that results in organomegaly. ${ }^{1}$

Due to a higher risk of systemic complications, patients with acromegaly experience increased the rate of morbidity and mortality. ${ }^{2,3}$

Cardiovascular manifestations such as congestive heart failure, hypertension, and coronary artery disease are common complications in patients with acromegaly and cause $60 \%$ of the deaths in these patients. ${ }^{4}$ The severity of cardiovascular manifestation related to the $\mathrm{GH}$ hypersecretion duration and mostly occurs in older patients with insufficient controlled acromegaly. ${ }^{5}$

Recent studies showed the therapeutic efficacy of the early intervention, either surgical or medical, on systemic complications of acromegaly. ${ }^{6-9}$

However, acromegaly is a chronic syndrome lasting decades, and systemic complications may occur over the lifespan of patients. There is limited information regarding the effect of surgical resection of pituitary adenoma on cardiovascular comorbidities such as cardiomegaly in patients with acromegaly.

The goal of this study was to determinants the incidence of cardiomegaly in patients with acromegaly and the potential effect of therapeutic intervention in improving such complications.

\section{Materials and Methods}

A total of 160 patients with acromegaly due to pituitary adenoma participated in this study. Acromegaly diagnosed was based on clinical manifestations, age-adjusted plasma 
IGF-I, and insuppressible GH serum levels during an oral glucose tolerance test. Chest X-ray and electrocardiogram and was obtained from all patients before and six months after surgery. The presence of pituitary adenoma confirmed by magnetic resonance imaging. In this study, cardiomegaly evaluated as a retrospective study of chest $\mathrm{X}$-ray (PA) and cardiothoracic ratio (CTR) measurement of cardiac and mediastinal size ratios.

The exclusion criteria consisted of previously known cases of cardiomyopathy, diabetes mellitus, secondary hypertension, and usage of any preoperative medical treatment for acromegaly before the study.

Trans-sphenoidal surgery performed in all cases, and hormonal evaluation has done before and 6 months after surgical intervention.

Plasma GH level was measured by immunoradiometric assay with a detection limit of $0.2 \mathrm{mU} / \mathrm{L}$, and plasma level of IGF-I by an RIA, respectively. IGF-I plasma levels of $\leq 463 \mu \mathrm{g} / \mathrm{L}$ (20-30 years), $\leq 370 \mu \mathrm{g} / \mathrm{L}$ (31-40 years), $\leq 306$ $\mu \mathrm{g} / \mathrm{L}(41-50$ years) and $\leq 247 \mu \mathrm{g} / \mathrm{L}$ ( $>50$ years) considered as normal.

Patients with GH levels under $2 \mathrm{mU} / \mathrm{L}$ after a glucose load (75 g) and normal age-corrected IGF-I-values after six months considered as well-controlled cases.

In cases with a $\mathrm{GH}$ level $>5 \mu \mathrm{g} / \mathrm{L}$, treatment continued by somatostatin octreotide after surgery. The patients were followed up in third and sixth months after surgery for evaluating symptoms relief and any case of tumor recurrence.

\section{Results}

During the study, 160 patients met the inclusion criteria. Their mean age was 39.1, and the standard deviation was 13.0. The patient's age ranged from 14 to 72 years old. The mean preoperative $\mathrm{GH}$ was $33.7 \mathrm{ml} / \mathrm{ng}$, which reached 5.7 $\mathrm{mL} / \mathrm{ng}$ after resection (Figure 1 ).

The mean pre-operative hormone IGF-1 was $794.1 \mathrm{ml} /$ ng, which decreased $395.6 \mathrm{ml} / \mathrm{ng}$ postoperatively (Figure 2 ). In this study, total tumor resection has done in 112 patients, subtotal resections in 42 , and partial resections in 6 patients (Table 1).

Of the 160 patients, 24 had preoperative cardiomegaly with a frequency of $15 \%$, of which $30 \%$ postoperatively had a partial improvement in cardiac symptoms, and $21 \%$ had no change.

\section{Discussion}

Acromegalic cardiomyopathy is a common finding in all patients with GH secretive pituitary adenoma. The severity of cardiomyopathy is associated with the duration of disease and GH serum level before treatment., ${ }^{1,10}$ Cardiac complications of excess $\mathrm{GH}$ secretion such as heart failure and arrhythmias are the leading causes of death in patients with pituitary adenoma. Cardiac structure change in $\mathrm{GH}$ adenomas that occur even in the subclinical stages, including cardiac hypertrophy,

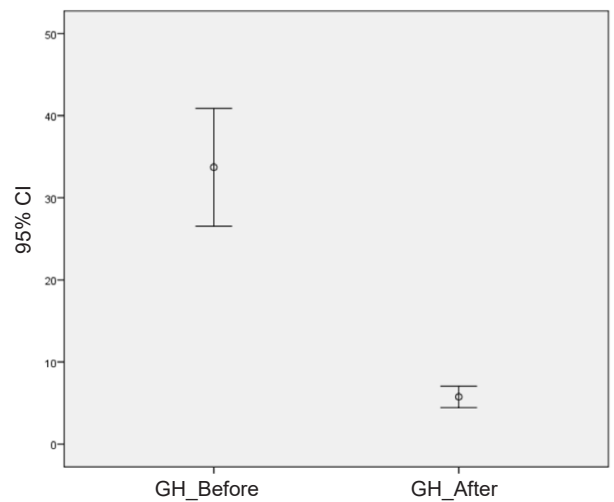

Figure 1. Mean Growth Hormone Serum Level Before and After Surgery.

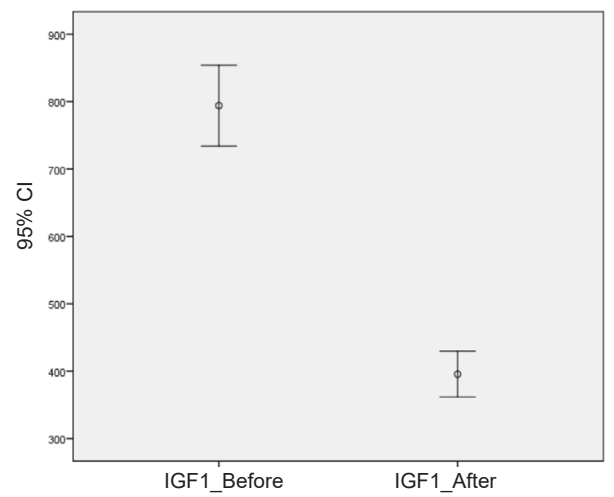

Figure 2. Mean IGF1- Serum Level Before and After Surgery.

Table 1. Size, Characteristics of Invasion, and Degree of Tumor Resection in 160 Patients With Pituitary Adenomas

\begin{tabular}{lll}
\hline Index & & Number of cases $(\%)$ \\
\hline \multirow{2}{*}{ Tumor Size } & Microadenoma $(<10 \mathrm{~mm})$ & $57(35.6)$ \\
& Macroadenoma $(>10 \mathrm{~mm})$ & $103(64.4)$ \\
\multirow{2}{*}{ Invasion } & Invasive neoplasm & $62(38.7)$ \\
& Non-invasive neoplasm & $98(61.3)$ \\
$\begin{array}{l}\text { Degree } \\
\text { of tumor }\end{array}$ & Total resection & $112(70)$ \\
Resection & Subtotal resection & $42(26.2)$ \\
\hline
\end{tabular}

chamber enlargement, ventricular diastolic dysfunction, and myocardial dysfunction. ${ }^{10,11}$ In this study, All of the patients had a high level of GH and IGF-1 and, $15 \%$ of them had cardiomegaly that measured by chest X-ray.

Prompt diagnosis and therapeutic intervention are essential strategies inpatient with pituitary adenoma high level of GH. The first option of treatment in patients with acromegaly is endoscopic resection of pituitary adenoma. ${ }^{12,13}$ Removing as much tumor tissue as possible to reduce the serum level of GH to the normal range is 
the primary goal of trans-nasal-sphenoidal endoscopic intervention. ${ }^{14}$ This approach could result in an optimal effect of tumor resection with minimum tumor residue. ${ }^{15,16}$

Cardiac structural abnormalities and dysfunctional are correlate with excessive secretion of GH hormone. ${ }^{17}$ Chronic elevation of serum GH and IGF-I due to pituitary adenoma could affect myocardium cell receptors, which increase myocardial sensitivity to intracellular $\mathrm{Ca}^{2+}$ and results to increase myocardial contractility. On the other hand, increased protein synthesis and cell volume in myocardial cells result in myocardial hypertrophy. Also, excess GH secretion results in myocardial degeneration and necrosis, interstitial collagen accumulation, and fibrosis that lead to cardiac remodeling. ${ }^{18}$

Currently, GH secretion control by surgical removal of the tumor is the treatment of choice in pituitary adenomas who complicated with acromegalic cardiomyopathy. In the current study, surgical resection of the pituitary adenoma and controlling GH secretion and serum levels of IGF-1, lead to recovered cardiac structure in some patients.

Our results show that myocardial structure abnormalities could be partially reversible in patients with GH secreting pituitary adenomas, but the best time for surgery and to preventing cardiac remodeling needs further study.

\section{Conclusion}

Cardiac manifestations in GH secreting pituitary adenomas involve needs the standardized approaches that include endoscopic surgery with medical therapy to maintaining the level of $\mathrm{GH}$ is required. Effective treatment is essential for pituitary adenomas that complicated by acromegaly cardiomyopathy, which may improve symptoms and results in a higher quality of life.

\section{Conflict of Interest Disclosures}

The authors declare that they have no conflict of interests.

\section{Ethical Statement}

The Ethics Committee approved the study protocol of the Shahid Beheshti University of Medical Sciences (Reference Code: IR.SBMU.RETECH.REC.1396.836). The participants were informed about the purpose of the research and its implementation stages and signed the informed consent; they also assured about the confidentiality of their information; Moreover, they were allowed to leave the study whenever they wish, and if desired, the results of the research would be available to them.

\section{Acknowledgments}

The authors would like to thank the Clinical Research Development Unit (CRDU) of Loghman Hakim Hospital, Shahid Beheshti University of Medical Sciences, Tehran, Iran, for their support, cooperation, and assistance throughout the study.

\section{References}

1. Bedogni G, Giannone G, Maghnie M, Giacomozzi C, Di lorgi $\mathrm{N}$, Pedicelli S, et al. Serum insulin-like growth factor-I (IGF-I) reference ranges for chemiluminescence assay in childhood and adolescence. Data from a population of in- and outpatients. Growth Horm IGF Res. 2012;22(3-4):134-8. doi: 10.1016/j.ghir.2012.04.005.

2. Berg C, Petersenn S, Lahner H, Herrmann BL, Buchfelder M, Droste $\mathrm{M}$, et al. Cardiovascular risk factors in patients with uncontrolled and long-term acromegaly: comparison with matched data from the general population and the effect of disease control. J Clin Endocrinol Metab. 2010;95(8):364856. doi: 10.1210/jc.2009-2570.

3. Colao A, Ferone D, Marzullo P, Lombardi G. Systemic complications of acromegaly: epidemiology, pathogenesis, and management. Endocr Rev. 2004;25(1):102-52. doi: 10.1210/er.2002-0022.

4. Mosca S, Paolillo S, Colao A, Bossone E, Cittadini A, ludice $\mathrm{FL}$, et al. Cardiovascular involvement in patients affected by acromegaly: an appraisal. Int J Cardiol. 2013;167(5):1712-8. doi: 10.1016/j.ijcard.2012.11.109.

5. Colao A, Ferone D, Marzullo P, Lombardi G. Systemic complications of acromegaly: epidemiology, pathogenesis, and management. Endocr Rev. 2004;25(1):102-52. doi: 10.1210/er.2002-0022.

6. Jaffrain-Rea ML, Minniti G, Moroni C, Esposito V, Ferretti E, Santoro A, et al. Impact of successful transsphenoidal surgery on cardiovascular risk factors in acromegaly. Eur J Endocrinol. 2003;148(2):193-201. doi: 10.1530/eje.0.1480193.

7. Annamalai AK, Webb A, Kandasamy N, Elkhawad M, Moir S, Khan F, et al. A comprehensive study of clinical, biochemical, radiological, vascular, cardiac, and sleep parameters in an unselected cohort of patients with acromegaly undergoing presurgical somatostatin receptor ligand therapy. J Clin Endocrinol Metab. 2013;98(3):1040-50. doi: 10.1210/ jc.2012-3072.

8. Minniti G, Moroni C, Jaffrain-Rea ML, Esposito V, Santoro A, Affricano $\mathrm{C}$, et al. Marked improvement in cardiovascular function after successful transsphenoidal surgery in acromegalic patients. Clin Endocrinol (Oxf). 2001;55(3):30713. doi: 10.1046/j.1365-2265.2001.01343.x.

9. Reyes-Vidal C, Fernandez JC, Bruce JN, Crisman C, Conwell IM, Kostadinov J, et al. Prospective study of surgical treatment of acromegaly: effects on ghrelin, weight, adiposity, and markers of CV risk. J Clin Endocrinol Metab. 2014;99(11):4124-32. doi: 10.1210/jc.2014-2259.

10. Sarkar S, Rajaratnam S, Chacko G, Chacko AG. Endocrinological outcomes following endoscopic and microscopic transsphenoidal surgery in 113 patients with acromegaly. Clin Neurol Neurosurg. 2014;126:190-5. doi: 10.1016/j.clineuro.2014.09.004.

11. Chanson P, Raverot G, Castinetti F, Cortet-Rudelli C, Galland F, Salenave S. Management of clinically non-functioning pituitary adenoma. Ann Endocrinol (Paris). 2015;76(3):23947. doi: 10.1016/j.ando.2015.04.002.

12. Carmichael JD, Broder MS, Cherepanov D, Chang E, Mamelak A, Said Q, et al. The association between biochemical control and cardiovascular risk factors in acromegaly. BMC Endocr Disord. 2017;17(1):15. doi: 10.1186/s12902-017-0166-6.

13. Mendoza E, Malong CL, Tanchee-Ngo MJ, Mercado-Asis L. Acromegaly with cardiomyopathy, cardiac thrombus and hemorrhagic cerebral infarct: a case report of therapeutic dilemma with review of literature. Int J Endocrinol Metab. 2015;13(2):e18841. doi: 10.5812/ijem.18841.

14. Kiseljak-Vassiliades K, Carlson NE, Borges MT, KleinschmidtDeMasters BK, Lillehei KO, Kerr JM, et al. Growth hormone 
tumor histological subtypes predict response to surgical and medical therapy. Endocrine. 2015;49(1):231-41. doi: 10.1007/s12020-014-0383-y.

15. van Varsseveld NC, van Bunderen CC, Franken AA, Koppeschaar HP, van der Lely AJ, Drent ML. Fractures in pituitary adenoma patients from the Dutch National Registry of Growth Hormone Treatment in Adults. Pituitary. 2016;19(4):381-90. doi: 10.1007/s11102-016-0716-3.

16. Kopchick JJ, List EO, Kelder B, Gosney ES, Berryman DE. Evaluation of growth hormone $(\mathrm{GH})$ action in mice: discovery of $\mathrm{GH}$ receptor antagonists and clinical indications. Mol Cell Endocrinol. 2014;386(1-2):34-45. doi: 10.1016/j. mce.2013.09.004.

17. Beckers A, Aaltonen LA, Daly AF, Karhu A. Familial isolated pituitary adenomas (FIPA) and the pituitary adenoma predisposition due to mutations in the aryl hydrocarbon receptor interacting protein (AIP) gene. Endocr Rev. 2013;34(2):239-77. doi: 10.1210/er.2012-1013.

18. Oki Y. Medical management of functioning pituitary adenoma: an update. Neurol Med Chir (Tokyo). 2014;54(12):958-65. 